\title{
Cultural Explanations for Academic Underachievement of Ethnic Minority Students at Secondary Level in Vietnam
}

\author{
Tran Ngoc Tien \\ Hoa Sen University, Vietnam
}

\begin{abstract}
Ethnic minorities in Vietnam face more disadvantages in accessing infrastructure, financial services, healthcare, and modern technology. In education, their children also have lower educational achievements as well as higher dropout and class repeating rates in comparison with their majority peers. This paper explores the reasons for educational underachievement of ethnic minority students at the secondary level in Lam Dong Province, Vietnam, through an investigation of factors related to the cultural aspects including cultural values, norms, beliefs, and practices towards education. It, furthermore, looks for the explanations of the gaps between the educational achievement of ethnic minority and majority children. The study was conducted in Lam Dong Province, Vietnam, through qualitative approaches with in-depth interviews, discussions observations and informal dialogues in 2010. Additional fieldwork was done in 2015 to provide a more comprehensive understanding and a fuller description of the issue. The findings show that ethnic minority students do not have sufficiently conducive conditions for high educational performance. They undergo the misconceptions and stereotyping from their majority peers for their physical and cultural differences. Furthermore, students do not have positive attitudes towards their learning and lack educational purposes. They hardly believe that education can be of any value or relevant to their future success. Ethnic minority students also lack sufficient encouragement from their parents and are encouraged to drop out of school to help their families in farming or to get married early. The findings confirm that cultural factors do have some impacts on the academic achievement of ethnic minority students.
\end{abstract}

Keywords: Cultural explanations, Educational underachievement, Ethnic minority students

\section{INTRODUCTION}

Vietnam is a multi-ethnic and multi-lingual country with officially recognized 54 ethnic groups speaking eight major language families. The estimated national population in the mid of 2015 was around 91,583,000 people. The ethnic minority groups make up for around 14.5 percent of the total population. This 54 ethnic minority group classification has been officially accepted and used since 1979 of which the ethnic Kinh or Viet is viewed as the majority and the other 53 ethnic groups are classified as the minorities (Pham Ngoc Chien, 2005).

The majority of ethnic minorities in Vietnam, except for ethnic Hoa and Khmer, reside in remote and mountainous rural areas (Imai \& Gaiha, 2007). They face more difficulties in approaching the market economy, good infrastructure, and financial sources. They are also supposed to have less political and economic power than the majority (Imai \& Gaiha, 2007) and have fewer opportunities for off-farm jobs and lower educational level (Van de Walle \& Gunewardena, 2001). Ethnic minority people are also subject to the conceptions such as backward, superstitious, primitive, conservative, unstable, or ignorant (Salemink, 2003; Jamieson et al., 1998; The World Bank, 2009).

As their residential territory is normally located in remote, isolated, and rural areas, ethnic minority people face more difficulties and challenges in accessing basic necessities of life such 
as electricity, roads, education, financial services and healthcare. Although accounting for only 14.5 percent of the total population, ethnic minorities make up 44.7 percent of the poor and 59 percent of the hungry (The World Bank, 2009). Data analysis from Vietnam's Household Living Standards Survey (VHLSS) for 2002 and 2004 also show that ethnic minority households were both poorer and more vulnerable than the ethnic Kinh and Hoa (Imai \& Gaiha, 2007). Van de Walle \& Gunewardena (2000) conclude that ethnic minorities in Vietnam are suffering from lower socio-economic advantages and lower living standards because they live in less productive areas characterized by difficult terrain.

Lam Dong is a mountainous province on the southern part of the Central Highlands. The estimated population of the province in 2015 is 1,259,255 people of which the ethnic minority people account for $23.0 \%$. The number of ethnic groups residing in the province is around 40 . Out of the ethnic minority population, approximate $71 \%$ are viewed as residential ethnic minorities or have their origins in the Central Highlands. Among the ethnic minority groups in the province, several of them are indigenous ethnic groups including Coho, Ma, Chu-ru, Mnong, Ra Glai, Xtieng, E-de, Ba-na, Gia rai, Ho Re, Xo Dang and Gie-Trieng. Most of the others, together with ethnic Kinh, have migrated or settled in the province in the last several centuries. Ethnic minority people in Lam Dong Province share the same living characteristics as the other ethnic minority people across the nation. They mainly reside in the in remote and isolated areas. Among the twelve districts and district-level cities of the province, around three percents of the population of the two municipal cities are ethnic minority people whereas the figures for the districts are from 20 percents. Two of them have the proportion of ethnic minority people more than 50 percents.

The demographic structure of the province has experienced a rapid change over the last several centuries. Several hundred years ago, there was a remarkable physical distance between Ethnic Kinh who mainly lived in the lowland or coastal areas and the other ethnic minorities primarily lived in the uplands. However, such distance seems to be vanished since the 20th century. Da Lat, the capital city of the province, was discovered on June 21st 1893 by a French doctor, named Alexandre Yersin. At that time, the territories of Da Lat City and Lam Dong Province was the home of the indigenous ethnic minority people such as Coho, Ma, Chu$\mathrm{ru}$, Mnong, Gia Glai. In the first years of 20th century, Da Lat was a deserted area with several tens of Kinh people. However, wars, redistribution, resettlement and immigration have changed the demographic structure of Vietnam including the territory of Lam Dong Province. Nowadays, ethnic Kinh has become the largest ethnic group in the province.

In the 2014-2015 academic year, the general education, including the primary, lower secondary and upper secondary levels, of the province had 237,031 students of which the number of students of ethnic minorities was 57,286 accounting for $24.2 \%$. However, the number of ethnic minority students attending school decreased correspondingly with the increase of the level of education. The largest proportion of ethnic minority students in the province was at the elementary level with $26.8 \%$ followed by lower secondary and upper secondary levels with $23.7 \%$ and $17.3 \%$ respectively. Besides that, ethnic minorities also have higher school dropout rates. Among the Kinh majority students, $0.1 \%$ of them dropped at lower secondary and $2.7 \%$ at upper secondary education while the figures for ethnic minority students giving up education at lower secondary and upper secondary levels during the academic year were $0.2 \%$ and $5.6 \%$ respectively. In terms of educational attainment, children of ethnic minorities lag behind their majority peers in terms of educational attainments. The figures for student performance in the 2014-2015 academic year from the provincial 
Department of Education and Training show that the ratios of ethnic minorities who were categorized "very good" and "good" were 26.3\% at junior high school and $19.3 \%$ at senior high school whereas the proportions for all students ranking "very good" and "good" at junior high school and senior high school were $57.8 \%$ and $53.2 \%$ respectively.

As education is considered as a means to impart skills and knowledge for the sake of the welfare of society, it helps ethnic minorities to acquire higher social value, norms, status and knowledge, to improve their power, and to integrate more actively in social, economic, and cultural issues (Rury, 2005). Education can also improve individual's power and socioeconomic status. It is strongly connected to social development and helps people to participate in the process of social, economic and cultural integration (Mirowsky \& Ross, 2003). Furthermore, education appears to be a bridge to connect people with standard norms and values (Coenders \& Scheepers, 2003). Hirschman \& Lee (2005) confirm that education has a role in improving the awareness of children towards society's norms, values and tolerance. It is a gateway for people to gain socioeconomic attainments and a predictor for a future job and high income.

For ethnic minority people, education can be considered as one way to recognize the presence of the ethnic minorities in society. Through education, ethnic minority people can integrate and assimilate into the mainstream. Through education, ethnic minorities' values in culture, language and identity can be preserved, developed and popularized. Educational achievement and its consequences in job opportunities, better income and future success are the ways to recognize and respect ethnic minorities (Heller, 1994). Tracing back to the history of educational development and the recognition of the ethnic minorities, education has been seen as a potent vehicle of reformation and social mobility. Education has helped ethnic minority people gain social, cultural and economic integration into the mainstream, improve their social status, have more opportunities to integrate, and insure higher political capacity (Rury, 2005). Hello, Scheepers \& Vermulst (2004) indicate that education is one of the most important factors playing the role of a socializing agent in reducing the prejudice of ethnic majority against minorities and it transmits liberal values aimed at reducing ethnic intolerance and prejudice. Higher educated people normally have better understanding of the social factors.

However, children of ethnic minority groups in Vietnam in general (The World Bank, 2009) and Lam Dong Province in particular have higher illiteracy rates, lower educational attainments and higher school dropout rates. This limits their chances to integrate more actively into the society and to access the benefits that education can bring to. As cultural assets can be seen as factors directly affecting ethnic minority students' educational performance (Bourdieu and Passeron 1990; Wiggan, 2007; Jæger, 2011), this paper explores these aspects in order to find out the reasons why ethnic minority students at the secondary levels in Lam Dong Province, Vietnam have lower educational attainments and higher school dropout rates and offers a precise and detailed understanding of the issues of educational underachievement of ethnic minority students to teachers, school leaders, education policymakers with the hope that ethnic minority children will have better conditions to gain higher educational achievement.

\section{THEORETICAL FRAMEWORK}

Low academic attainment of ethnic minority students, according to Tomlinson (1991), is a term generally used to make a comparison between ethnic minority and ethnic majority children on standardized group tests of ability and attainments, on individual IQ tests, or in school examinations. Researchers on the issue of ethnic minority students' academic underachievement often focus on the aspects of cultural and structural explanations including 
intellectual capacity, individual and familial aspirations, cultural differences, socio-economic backgrounds, family structures, parents' background, school peers, teachers, language problems, low self-esteem, prejudice, or lack of resources to offer an insightful understanding as well as theoretical explanations for the phenomenon (Kim, 2002).

Cultural orientation, according to Kim (2002), focuses on the importance of cultural values, norms, beliefs, and practices to search for the explanations of the gaps in the educational achievement of ethnic minorities and majorities. Kim also believes that cultural tradition is one of the factors for explaining the differences in the educational attainment of students. As the value of education is rooted in cultural practices and traditions, costs of schooling, and expectations for employment, the ethnic groups that place more value on education normally have better educational attainments. Gibson $(1984 ; 1991)$ asserts that the gaps in the educational attainments among students of different ethnicities arise from the differences in the educational opportunities originating in the differences of cultures. The assumptions are that ethnic minority students face more difficulties and disadvantages when learning in a school dominated by mainstream values. Furthermore, the remarkable differences in their home culture and school culture make their academic performance fall below the national norms.

Learning environment is another decisive factor affecting educational achievement. A child who lives in a conducive context to schooling tends to have better educational attainments (Eldering, 1997). An effective learning environment allows and motivates students to fully participate and engage in the educational system. Furthermore, learning environment will be more effective when the cultural values are recognized and used in the learning process. Students will have higher educational attainments if their cultures emphasize the value of education, hard work, and social solidarity and when education is considered as a key to achieve mobility, to have job security, and to gain future success (Kim, 2002; Ngo \& Lee, 2007).

Students themselves will have better educational achievements if they have positive attitudes, educational purposes, and higher abilities at school (Eldering, 1997; Chavous et al., 2003). Chavous et al. (2003) also suggest that educational aspirations and educational attainments are positively related. Students who recognize the value of education, and who have educational purposes will have higher academic success. Furthermore, students who believe that education is relevant to their life outcomes and future success will have higher school completion rates and better performance.

Theories of race and ethnic stratification believe that inadequate socioeconomic conditions and discrimination lower academic attainments of ethnic minority children (Hirschman \& Lee, 2005). The discrimination from peer pressure and popular culture influences children's academic attainments, causes negative impacts on their educational performance, and makes them consider education as less important (Rong \& Brown, 2007). Coenders \& Scheepers (2003) discover that there is a negative correlation between educational attainment and ethnic prejudice. People with high education are found to have less prejudice and discrimination towards ethnic out-groups than those who are less educated. Moreover, those who have better education are seen as less prone to in-group favoritism. People, who belong to lower social classes and have lower income, display higher degree of ethnic exclusionism.

Ogbu, in his researches on ethnic identity and academic achievement, discovers the oppositional attitudes that ethnic minority children have towards whatever considered belong 
to the major groups. As the culture is different, students of ethnic minorities may behave differently in their schooling. They refuse performing well academically as they avoid their ethnic friends to classify them as belonging to the dominant groups. Such oppositional attitudes aim to deal with the tensions between schools' requirement to behave in the right way and perform well educationally and their peer groups' demand to do in a reverse way called the burden of acting White (Ogbu, 2004; Ogbu, 2008).

Chavous et al. (2003), on the other hand, explores that youths' beliefs about self and race are related to their educational and social developments. Children who have strong group pride and positive beliefs about society's views tend to have more positively academic beliefs, higher motivations and stronger engagement in schooling. Ethnic minority youths who perceive less social inequity against their groups feel that education is meaningful and relevant. They also have higher motivation in their school engagement and persistence. However, youths within the groups that are prejudiced and discriminated by the dominant groups may protect their self-concepts and their values by devaluing what do not belong to them.

In a joint research aiming at searching for the obstacles blocking ethnic minority girls from their transition to lower secondary schools from primary schools, UNICEF Vietnam, MOET of Vietnam, \& UNESCO Vietnam (2008) show that parental perceptions of the economic value of education, early marriage and perception on education for girls are the main factors associated to cultural aspects obstructing ethnic minority girl from gaining better educational performance. The report also argues that although these factors do not play a crucial role in deciding the success of an ethnic minority girl in their schooling, these cultural aspects do have some influence on ethnic girls' educational performance.

\section{METHODOLOGY}

The research used qualitative methods with in-depth interviews, group discussions, observations and informal dialogues. Purposeful sampling was selected with maximum variation techniques to select informants of different perspectives and characteristics. The main participants for the study were ethnic minority in-school students at secondary education levels belonging to three major indigenous ethnic groups of Lam Dong Province, namely Coho, Ma and Chu-ru1. Another main group of the research participants was the ethnic minority children who had stopped their schooling at secondary levels of education within the last three years. The other research informants were those related to or thoroughly understood the issues of ethnic minority students' education achievement. They were ethic minority students at tertiary education, students' parents, teachers, commune leaders, and village heads.

A total of 45 interviews and group discussions were conducted. The questions focused on the ethnic minority students and their households' difficulties in getting education, their responses to these difficulties, and their opinions towards education. Many other informal conversations and anecdotal observations were also conducted to confirm the findings from interviews and group discussions. Before conducting the fieldwork, those in charge of ethnic minority children's authority such as school principals and family heads were asked for the permit to

\footnotetext{
${ }^{1}$ Coho, Ma and Chu-ru are the three biggest indigenous ethnic groups in Lam Dong Province, Vietnam. They are those who best represent of the indigenous ethnic groups in the province in terms of socio-cultural and economic conditions. Their children experience lower educational achievement in comparison with the children of ethnic majority and other main ethnic groups.
} 
conduct the interviews, group discussions and observations in their schools or with their children.

The field research was carried out in two separated periods, from February to August, 2010; and from February to June 2015, in three districts and the capital city of Lam Dong Province. These places were selected among the ten districts and two district-level cities of the province. The criteria for selecting the research sites included the diversification of ethnic minority groups, the percentage of ethnic minority people in the communes, and the differences in terms of socio-economic structure, geography and distance to the provincial capital.

Questions used for interviews and group discussions were semi-structured as the semistructured questions allowed the researcher to cover all the topics needed for the study as well as to explore respondents' experiences, perceptions, opinions, feelings, and knowledge in the discussed issues (Patton, 2002). According to Bernard, "in situations where you won't get more than one chance to interview someone, semi-structured interviewing is best. It has much of the freewheeling quality of unstructured interviewing, and requires all the same skills, but semistructured interviewing is based on the use of an interview guide" (Bernard, 2006, p. 212).

The interviews and group discussions were conducted in Vietnamese and recorded by an audio recorder. In the cases that the participants hesitated to be recorded, note-taking was used. To ensure the ethical fieldwork, the participants were informed of the aims of the research and asked for their consent to participate in the study. They were also informed of the research confidentiality that the information provided as well as their identities would be kept confidentially and used for this study only. The research informants were also encouraged to be honest and to feel free and safe in providing the information.

After the interviews and discussions had been conducted, all the data were transcribed keeping the participants' own words with the identifying information such as time, setting and participants. The transcriptions were reviewed to get the common sense of the data collected. Before the transcribing was done, a list of potential codes was created based on the reviews of relevant studies and based on the research objectives. This phase of coding helped to identify the potential themes for the study. Then, data was reviewed carefully and some adaptations were applied in terms of coding. Some codes were added, and some were combined or split. The ideas that appeared regularly in the interviews were highlighted and then categorized into major and minor themes for analyzing. These themes were then reviewed to see the similarity and differences with those gained from the previous researches. The final list of themes was defined and named. Themes that made the most meaningful contributions to the impact of cultural factors on educational achievement of the ethnic minority students were selected for this paper.

\section{FINDINGS AND DISCUSSION}

As an ethnic minority individual, family or group may culturally value education differently in terms of norms, beliefs and practices (Kim, 2002), families of ethnic minority in Lam Dong Province consider economic outcome and employment possibilities as the utmost goal of their children's schooling. This reflects the traditional practices and the local labour market conditions. Additionally, the custom of getting marriage early and undervaluing education for girls are other barriers preventing ethnic minority students from attaining good educational performance. Other factors related to the cultural issue hampering ethnic minority students from having higher academic success are peer pressure and peer teasing. These occur when 
the in-school students do not have adequate motivation for education and when there are the dissimilarities in custom, lifestyles, native languages, skin color, hairstyle and accents between the majority and minority students. The lack of confidence and educational motivation are also discussed in this paper to look for the causes of low educational performance of ethnic minority students in the province. As ethnic minority students are sensitive to others' teasing, they become shy, timid and less confident in their schooling.

\section{Lack of beliefs in educational value}

When parents think that sending their children to school is a kind of investing their money in their children's future, they hope that education can lead to direct benefits in poverty reduction and employment ability. Buchmann and Hannum (2001) believe that parental aspiration for education in developing countries is directly linked to the economic outcome. Parents make their choice for their children' education based on the possibility of economic returned to the family. Ethnic minority families those who are living in poverty may have the tendency valuing education if it is relevant or directly connected to employment opportunities enabling them to overcome poverty. For them, basic education or literacy is necessary and enough for children. However, education at high levels should be closely linked to the economic outcome. Education will not be considered value if it fails to provide economic returns and help them to escape economic difficulties. However, in the current economic conditions, the opportunities for off-farm jobs in the region are limited and education cannot directly bring any financial outcome. Consequently, there would be less parental aspiration for their children education, and there was a lack of parental encouragement for their children's good educational performance. There were some cases reported that when the teachers went to convince the parents to let their children to continue their education, what the teachers got from the parents was the indifferent attitude towards their children's temptation of giving up schooling. The answers were "Never come here again. He (the student) does not want to go to school. It is useless to come here." or "He does not want to study. Let him stay at home. We have big farmland." Some parents even encouraged their children to drop out of school to help families in the farm work. According to them, it is better if students drop out of school and do something to help the family. An ethnic minority teacher who had more than ten years teaching in Di Linh District explained:

Most of the children of ethnic minorities remain unemployed after graduation. They have to wait from years to years and then return to their traditional occupation (farming jobs). They cannot rely on their families after graduation any more. They need jobs for their own living expenses. But the situations are too difficult. As students without employment after graduation are still high, their parents have to make a choice between sending their children to school or let them stay at home. Unfortunately, they let their children stay at home.

He also added that not only the students of ethnic minorities but also children of ethnic majority share the same situation. However, parents of ethnic majority children are normally more active, have better economic conditions and wider social connections. The possibilities for them to have jobs are higher. A mother of an ethnic minority child who had just given up schooling at the grade of ten after an academic year of poor performance said when asked why she did not let her children going to school, "that is his choice. I cannot do anything else. But what is education for? He cannot still find a job even if he graduates so we let him stay at home to save money." A teachers working in an upper secondary school in Di Lich District recalled "When I visited one of my students' house who had just stopped studying and intended to give up schooling to persuade his parents let him return to school, the mother said that let him be home to help the family. They cannot sell knowledge or exchange for food." 
When parents see that education has no purpose, they believe that basic level of education seems sufficient for them. People coming from poverty think that education cannot provide them food and other necessities in daily life as an ethnic minority female said "we cannot exchange knowledge for food" or "we cannot eat books". As education is not related to immediate wage labor or income, they think that investing in education cannot bring any benefits. They encourage their children to stay home and look for jobs. Dramatically, many ethnic minority graduates from tertiary education cannot find jobs. They said that jobs are only available if they have money, status or connections. They realize that although having good education the financial conditions of the family cannot be changed in the positive directions. A father of two ethnic minority children at lower secondary school in Lac Duong District said, "Sending children to school costs lots of money. However, when they complete and have degrees, they cannot get jobs. We need to have a wheel (money) to run. As we do not have, there are lots of graduates from the vocational training schools and colleges without jobs in the village."

As ethnic minority people tend to live in the remote and rural areas, off-farm jobs, mainly in the government, are limited and hard to access. Furthermore, the fact that a wide spread of the university graduates cannot find jobs discourages parents from sending their children to school. A father of two ethnic minority students explained why he would not let his children continue education at tertiary education as a friend of him sold his farmland for his son to study at the teachers' training college. Unfortunately, his friend's son could not find a job and there was also no farmland left for farming. This bitter lesson discouraged him from letting his son continue education. Some people even thought that the more education they got the poorer they would be. A teacher of a lower secondary school recalled that one of his formers students who had just graduated from a local college once told him that while he was unemployed and had spent quite a long time and a large amount of money on his education, his friends gave up school early got married and had a better life. A father of three children at the age of secondary schooling of which the eldest had given up schooling at the grade of eleven explained that he could not afford the schooling for all of his children. The eldest was encouraged to stay at home to help the family in farming and taking care of his siblings. The father mentioned that financial difficulty is one reason; however, the main one was that the possibility to help his son to get a job was too low.

\section{Early marriage}

Ethnic minority people have the tendency of getting married early. They start thinking about getting married at the age of sixteen. In many cases, female teenagers get married right after giving up school at the age of upper high school. When the girl reaches puberty, their parents think that they are at the marriageable age and often ask them to drop out of school and prepare for the marriage. The tradition of getting married early can lead to many social problems of which education is whether directly or indirectly influenced. By getting married early, ethnic minority children limit their opportunities accessing education and hesitate to struggle for good educational performance. A vice-principal of a secondary school in Don Duong District said that the cases of ethnic minority students in his school dropped out of school to get married were not rare, almost every year. When being asked why he dropped out of school and got married at the age of 16, a male informant of ethnic Coho at said "my parents told me to get married to have someone to help in the farming, to do the housework and to have children." One female informant explained why she got married at the age of 16, "my parents asked me to get married. I just followed their requirement. My friends in the village had got married already." Life of the young couples seemed not to be easy. They had no jobs 
and lived on some small pieces of farmland given by the families or they had to be dependent on their parents. A village head of a remote commune explained, "getting married early and having lots of children are traditions of ethnic minority people rooted long time ago. It is not easy to convince them to change." A teacher who had around 15 years of teaching and being in charge of homeroom teacher recalled that there had been several cases of ethnic minority students gave up schooling to get married. The school had already went to their house to persuade their parents to let their children continue education, but it was impossible for the school to deal with the issues as the custom of getting married early and disvaluing education had been ingrained deeply in their minds.

Furthermore, early marriage for girls means providing labor force for their husbands' families. There have also been some perceptions existing among the ethnic minority parents that boys need to be educated for the possibilities of future career because they are the main bread earners of the families. Girls, on the other hand, do not need a social life. After getting married, girls normally join their husbands' families. They take care of their husbands' family members and contribute their labor to their husband's families. This makes ethnic minority parents think that education would bring benefits to their daughter's husband families rather than for their own. They hesitate to send their daughters for education at lower and upper secondary levels. Literacy for them is enough and high education is not necessary. Furthermore, a village head in a remote commune in Lac Duong district said that "girls are not set as the priority for schooling. They are the first to stop going to school if the families can't afford for both." He also added that girls would stay at home to take care of the families so high education is considered not necessary.

\section{Peer pressure and peer teasing}

Peer pressure also affects educational attainment of ethnic minority students. As they do not put high value in education, they become less eager for education when their close friends drop out of school. They easily follow their out-of-school friends to join in some other activities rather than attend schools. A teacher in Di Linh District said:

The in-school ethnic minority children are influenced strongly by the out-of-school children. The out-of-school students consider the success of encouraging in-school children to drop out school as a trophy. Several weeks ago, whenever the break time came, a group of out-of-school children entered the school, wandered outside the classrooms and induced the other children to play truant and join their groups to play billiards, football or to go to the coffee shops. While the in-school students feel fed up with studying, the out-of-school children are having fun. They would play hooky and join the out-of-school groups during the courses that they do not feel like to study.

Another teacher in Di Linh District added that the influence of the out-of-school children on their in-school peers were tremendous. The children after giving up school can help their families in the farm work. Furthermore, they can hoe land, spray insecticide or water the plantations for others and earn VND 100,000 (US\$ 5) a day. As a result, they have money to buy new clothes or footwear, play billiards or go to the coffee shops. Those who are in school with low educational performance think that dropping out of school is funnier and more beneficial. This makes the in-school students easier to give up studying and join the out-of-school groups.

Students of ethnic minorities reported as being teased or insulted by their classmates. Students of ethnic minority and majority are dissimilar in terms of culture. They do not share the same custom, lifestyles, native languages, skin color, hairstyle and accents. When these dissimilarities are not accepted and do not get full understanding from the mainstream 
students, they became the subjects of tease and insult. Cases were also reported by ethnic minority students that they were teased for their physical maturation, and for their lower educational performance. A group of ethnic minority students at lower secondary school said that they were teased by their classmates. These students teased and spoke scornfully of their darker skin and lower educational attainments. An ethnic minority girl at upper secondary school said that ethnic minority girls in their class were teased for their more physical maturation. Ethnic minority students normally entered school at older ages. Their parents thought that the children were too young and not strong enough to go to school. Furthermore, they could not speak Vietnamese so they were not ready, and the school was too far from home so it was not convenient and safe for the children to go by themselves. At the ages of lower and upper secondary schools, these late enrolment children were more physically developed. This physical maturation made them less confident and more embarrassed.

\section{Low self-esteem, confidence and motivation}

Several problems faced by ethnic minority students resulting in poor educational attainments were due to their embarrassment, low self-esteem, lack of confidence and educational motivation. Teachers in the interviews indicated that ethnic minority students seemed to be shy, timid and less confident. They had high inferiority complex and were very sensitive to others' teasing. They might give up their schooling if feeling ashamed. Furthermore, due to lack of confidence, ethnic minority students passively participated in lessons or schools' extracurricular activities. They rarely interacted with teachers and were less likely to express their ideas in the class. Teachers faced many difficulties in getting the feedback from students' comprehension. Some ethnic minority students were reported as sitting silently in class without doing anything. They did not participate in class activities including taking notes, doing assignments, or giving answers when being called upon by the classroom teachers.

Ethnic minority students were unlikely to be motivated in getting better educational attainments. In the interviews, they seem satisfied with their performance at school whatever it would be. They did not have any clear ideas for their future career or any plans for their further education. Their choices of future career were not much related to education. A group of ethnic minority students at lower secondary level said when being asked what kinds of jobs they what to do after high school graduation that they had no ideas for future career or wanted to be motorcycle repairer which does not need to have high educational level. One student mentioned that he wanted to be a doctor but he did not know which subjects he need to master to become a doctor or which schools he needed to enroll to become a doctor. A teacher at a lower secondary school who had close relationship with ethnic minority students said that ethnic minority students did not believe in the value of education. This was because education could not bring any differences for them in the local context. Furthermore, ethnic minority students in his class confided to him that their friends who had given up schooling early had already married and had better life whereas they were struggling with the schooling. As education could not guarantee an off-farm job and a better life in the future, ethnic minority people believed that basic literacy was enough. What they expect from education was to know how to read and write.

\section{CONCLUSION}

As each ethnic groups might have its own culture, traditions, customs and socioeconomic conditions, this raises the question whether ethnic minority children in Lam Dong Province, Vietnam share the same or different difficulties as the children of other ethnic minority groups in Vietnam or in the global context in gaining educational achievement. From this viewpoint, 
this paper highlights cultural explanation for low educational attainments of ethnic minority children in Lam Dong Province. The factors discussed related to the lack of beliefs in the values of education, the tradition of getting married early, peer pressure and peer teasing, and low self-esteem, confidence and motivation for educational achievement. The lack of beliefs in the values of education was discovered to play the biggest role in discouraging students from getting higher educational achievement. This reflects the economic condition and educational expectation of the ethnic minority people in the region. The tradition of getting married early also limits the schooling opportunities of ethnic minority children. For students who still recognize the value of education, there are a numerous factors in the learning environment discouraging them from struggling for better academic performance.

The paper also shows that the problem of academic underachievement of ethnic minority students in Lam Dong Province, Vietnam is a complicated issue. The reasons are varied. They do not merely come from the students themselves but they are the consequences of the differences in the cultural, geographical and economic backgrounds that do not create a conductive learning environment for the students. Furthermore, education, to some extent, is not accessible for all children and fails to help ethnic minority students integrate more actively into the society in terms of gaining higher social status and improving their economic condition in the context of the province. The findings of this study are consistent with other previous researches. Children of ethnic minorities do not have favorable conditions to concentrate on studying and gain higher educational performance.

\section{References}

Bernard, R. H. (2006). Research methods in anthropology: qualitative and quantitative approaches. New York: AltaMira Press.

Bourdieu, Pierre and Jean-Claude Passeron. 1990. Reproduction in Education, Society and Culture. London: Sage.

Buchmann, C., \& Hannum, E. (2001). Education and stratification in developing countries: A review of theories and research. Annual review of sociology, 77-102.

Chavous, T. M., Bernat, D.H., Schmeelk-Cone, K., Caldwell, C.H., Kohn-Wood, L. \& Zimmerman, M.A. (2003). Racial identity and academic attainment among African American adolescents. Child Development, 74(4), $1076-1090$.

Coenders, M. \& Scheepers, P. (2003). The effect of education on nationalism and ethnic exclusionism: An international comparison. Political Psychology, 24(2), 313-343.

Eldering, L. (1997). Ethnic minority students in the Netherlands from a cultural-ecological perspective. Anthropology \& Education Quarterly, 28(3), 330-350.

Gibson, M. A. (1984). Approaches to multicultural education in the United States: Some concepts and assumptions. Anthropology \& Education Quarterly, 15(1), 94-119.

Gibson, M. A. (1991). Minorities and schooling: Some implications. In M. A. Gibson and J. Ogbu eds. Minority status and schooling: A comparative study of immigrant and involuntary minorities. New York: Garland Publishing.

Heller, M. (1994). Crosswords: Language, education and ethnicity in French Ontario. Berlin: Mouton De Gruyter.

Hello, E., Scheepers, P., \& Vermulst, A. (2004). Association between educational attainment and ethnic distance in young adults: Socialization by schools or parents? Acta Sociologica, 47(3), 253-275.

Hirschman, C. \& Lee, J. (2005). Race and ethnic inequality in educational attainment in the United States. In Rutter, M. \& Tienda, M., Ethnicity and causalmechanisms (pp. 107-138). Cambridge: Cambridge University Press.

Imai, K., \& Gaiha, R. (2007). Poverty, inequality and ethnic minorities in Vietnam. Manchester: Brooks World Poverty Institute.

Jæger, M. M. (2011). Does cultural capital really affect academic achievement? New evidence from combined sibling and panel data. Sociology of Education, 84 (4), 281-298.

Jamieson, N. L., Cuc, L. T. \& Rambo, A. T. (1998). The development crisis in Vietnam's mountains. Honolulu: EastWest Center. 
Kim, R. Y. (2002). Ethnic differences in academic achievement between Vietnamese and Cambodian children: Cultural and structural explanations. The Sociological Quarterly, 43(2), 213-235.

Mirowsky, J. \& Ross, C.E. (2003). Education, social status, and health. New York: Aldine De Gruyter.

Ngo, B., \& Lee, S. J. (2007). Complicating the image of model minority success: A review of southeast Asian American education. Review of Educational Research, 77, 415-453.

Ogbu, J. U. (2004). Collective identity and the burden of "acting White" in Black history, community, and education. The Urban Review, 36(1), 1-35.

Ogbu, J. U. (2008). The history and status of a theoretical debate. In Ogbu, U., Minority status, oppositional culture, and schooling (pp. 3-28). New York and London: Routledge.

Patton, Q. M. (2002). Qualitative research and evaluation methods. California: Sage Publications.

Pham Ngoc Chien. (2005). Koho ethnic minority in Lam Dong: Anthropological study of ethnicity and culture (Nguoi Koho o Lam Dong: Nghien cuu nhan hoc ve dan toc va van hoa). Ho Chi Minh City: Youth Publisher.

Rong, X. L., \& Brown, F. (2007). Educational attainment of immigrant and non-immigrant young Blacks. In Paik, J.S. \& Walberg, J.H. (Ed.), Narrowing the achievement gap: Strategies for educating Latino, Black, and Asian students (pp. 91-107). New York: Springer.

Rury, L. (2005). Education and social change: themes in the history of American schooling. New Jersey: Lawrence Erlbaum Associates.

Salemink, O. (2003). Enclosing the highlands: Socialist, capitalist and protestant conversions of Vietnam's central highlanders. Amsterdam: Vrjie University.

The World Bank. (2009). Country social analysis: Ethnicity and development in Vietnam. Washington, DC: World Bank.

Tomlinson, S. (1991). Ethnicity and educational attainment in England: An overview. Anthropology \& Education Quarterly, 22(2), 121-139.

UNICEF Vietnam, MOET of Vietnam, \& UNESCO Vietnam. (2008). The transition of ethnic minority girls from primary to secondary education. Hanoi: UNICEF Vietnam, MOET of Vietnam, UNESCO Vietnam.

Van de Walle, D., \& Gunewardena, D. (2001). Sources of ethnic inequality in Viet Nam. Journal of Development Economics, 65(1), 177-207.

Wiggan, G. (2007). Race, school achievement, and educational inequality: Toward a student-based inquiry perspective. Review of Educational Research, 77(3), 310-333. 